\title{
Experimental study on elements diffusion of carbide tool rake face in turning stainless steel
}

\author{
Minli ZHENG*, Jinguo CHEN***, Ze LI*, Wei ZHANG*, Pengfei LI* and Haihe XIE** \\ * College of Mechanical and Power Engineering, Harbin University of Science and Technology \\ No.52 Xuefu Road, Nangang District, Harbin 150080, China \\ E-mail: zhengminli163@163.com \\ **School of Electrical and Mechanical Engineering, Putian UniversityPutian351100, China \\ No.1133 Xueyuan Road, Chengxiang District, Putian351100, China
}

Received: 19 November 2017; Revised: 9 January 2018; Accepted: 11 July 2018

\begin{abstract}
Affected by high temperature and pressure during the process of cutting stainless steel, the affinity element diffusion of tool-chips leads to the appearance of adhesion on the rake face, which eventually results in adhesion failure of the tool. In this study, we determined the formation of tool-chip adhesion during the cutting process using a cutting test; and put forward an experimental scheme of the element diffusion for clamped and welded specimens of the tool and workpiece. Fick's second law was used to develop a theoretical model of element diffusion to analyze the effect of tool-chip adhesion on the Fe and W element diffusion coefficient of Fe and W. The hardness of the tool surface was measured and analyzed after the diffusion experiment. The results showed that the tool-chip adhesion on the rake face of the tool was similar to pressure diffusion welding and that the tool-chip adhesion on the rake face directly affected the diffusion concentration of $\mathrm{W}$, but had little effect on the diffusion concentration of $\mathrm{Fe}$. In addition, the diffusion coefficient of $\mathrm{Fe}$ or $\mathrm{W}$ in the tool-chip adhesion is always greater for stick-welding than for non-stick-welding. The research results are of great significance for improving the cutting performance and tool life.
\end{abstract}

Keywords : Element diffusion, Tool-chip adhesion, Carbide tool, Stainless steel, Hardness

\section{Introduction}

When using carbide tools to cut stainless steel, the high temperature and pressure caused by the large feed rate and cutting depth, the elements in stainless steel increase the affinity between the elements in the stainless steel and the cutting tools; as a result, element diffusion, melting, and recrystallization occur and cause the welding of the tool and the workpiece. When the shear force cannot remove the adhesion, a solid adhesion layer is formed, as shown in Fig. 1.The bonding force between the adhesion layer and the tool base is weakened and when the binding force is less than the shear force, the material in the adhesion layer is torn and removed in the form of chips, resulting in the failure of the tool contact with the workpiece surface and decreasing the service life of the tool. Therefore, it is important to improve the cutting performance of the tool by studying the diffusion behavior of the tool-chip elements in the cutting process.



(a)

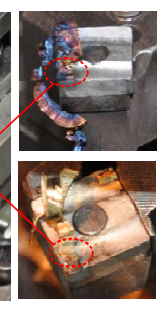

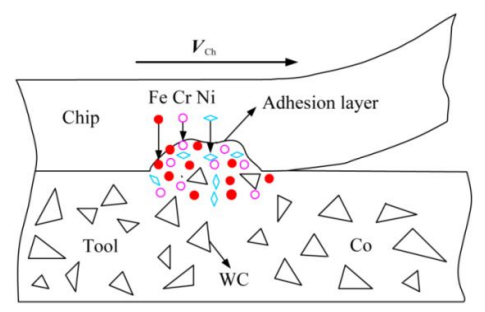

(b)

Fig.1 The adhesion layer formed in the cutting process; (a) cutting tool bonded with the workpiece during the cutting process of stainless steel; (b) affinity diffusion between $\mathrm{Fe}, \mathrm{Cr}$, and $\mathrm{Ni}$ and the elements in the cutting tool 
When the cutting parameters are altered during the cutting process, the cutting force and the generated heat change, which affects the element diffusion process. The diffusion mechanisms have been explored using scanning electron microscopy (SEM) and energy spectrum analysis to observe the element diffusion. Domestic and foreign scholars have conducted many research studies on element diffusion and tool diffusion wear. Bai et al., (2016) studied the temperatures and stress at the tool/chip interface and the diffusion behavior of a $\mathrm{Co} / \mathrm{Ti}$ interface at the atomic level and showed that the cutting speed had a significant effect on the element diffusion at the $\mathrm{Co} / \mathrm{Ti}$ interface. Calatoru et al., (2008) found that high temperatures generated during the cutting process activated the diffusion of aluminum into the tool material, resulting in the formation of a eutectoid-containing Co aluminide (AlCo) with Co used as the binder; this process is an unusual and not well-known form of diffusion wear that prevents manufacturers to make full use of tungsten carbide tools for high-speed machining of aeronautical aluminum. Rashid et al., (2016) studied all possible tool wear mechanisms involved in the use of uncoated carbide cutting tools to machine Ti6Al4V titanium alloy at a cutting speed of $150 \mathrm{~m} / \mathrm{min}$ under dry cutting conditions; the authors found that adhesion, diffusion, attrition, and abrasion were the mechanisms associated with the cratering of the rake surface of the cutting tool. Molinari and Nouari (2002) found that the temperature, cutting speed, initial concentration of the diffusion element, and the cutting tool and workpiece material were the main factors influencing the degree of diffusion. Sun and $\mathrm{Lu}$ (2016) investigated the effects of brazing time on the element diffusion and bonding strength of vacuum-brazed joints of 15-5PH stainless steel using the filler metal $\mathrm{BNi}-2$; the results showed that the brazing time determined the concentration of the diffused elements. The cutting process is always accompanied by element diffusion and the change in the cutting parameters affects both the cutting temperature and the cutting force. However, there are few studies on the effects of temperature changes on the element diffusion.

It was found that the element diffusion affected the surface of the cutting tool if the rake face of the tool had a strong bond or was broken. Matsui et al., (2012) observed and analyzed cutting tools during the cutting process of a mild steel surface and evaluated the microstructure and element distribution of the residue at the tool/workpiece interface; the authors found that the residue consisted of fine ferrite grain that was produced by severe plastic deformation and the tungsten carbide (WC) particles of the cutting tool of the exhibited serious wear and tear. Soković et al., (2004) studied the element diffusion at the interface of a coated cermet tool and a workpiece and found that the element diffusion process resulted in a change in the composition of the boundary layers of the tool, which increased the mechanical damage of the cutting edge. Hao (2014) studied the material response to different cutting speeds at the tool-chip interface and the effect on tool wear by using physical vapor deposition-coated carbide tools to machine Inconel718; the results showed that the newly generated material reduced the tool hardness and bond strength of Co and flakes of wear debris fell from the tool substrate, which increased the tool wear. Zhang et al., (2009) determined that the removal of WC particles were due to Co diffusion that dominated the crater wear mechanism on the rake surface of the cutting tool rather than the diffusion of the W and C atoms. Deng et al., (2011) studied the adhesion on the tool rake and flank face and observed an adhesive joint interface between the workpiece materials and the tools; the element diffusion occurred from the tool rake face to the adhering layer (vice versa) through the adhesive joint interface, which resulted in the loss of elements from the tool and microstructural changes. Deng et al., (2008) studied the diffusion phenomenon of Co and WC using carbide cutting tools for dry cutting of titanium alloy Ti-6Al-4V and pointed out that the element diffusion at the tool-chip interface changed the composition of the cutting tool material and structure, thereby increasing the tool wear. Ramirez et al., (2017) studied the diffusion wear of a WC-10\% Co cemented carbide tool using diffusion couple and cutting experiments. By using different durations of heat preservation in the diffusion couple experiment, it was discovered that the tool side close to the diffusion interface was a Co-rich area where no WC was found on the titanium side, whereas the tool elements were also found in the bonded titanium layer on the tool surface after the cutting experiment; this confirmed that the dissolution and compositional changes of the WC in the cemented carbide tool degraded the mechanical properties of the tool surface, eventually leading to crater wear. Chen et al., (2017) studied the tool-chip stick-welding approach and welding layer formation conditions of the carbide cutter's rake face and obtained the trends in the cutting temperature and the state of the stick-welding for different parameters. Tong et al., (2009) put forward the concept of metal gradient structure shafts and investigated the microstructure and diffusion behavior of $\mathrm{Cr}$ and the variation in the interfacial micro-hardness of a $25 \mathrm{Cr} 5 \mathrm{MoA} / \mathrm{Q} 235$ clad shaft. The results of these studies indicate that element diffusion plays a very important role in the wear and even breakage of the tool and affects the formation of adhesion on the surface; however, research is lacking on whether sticking adversely affects the element diffusion and the extent of the adhesion effect. 
The review of the existing studies shows that dissimilar materials that are in contact with or bonded to each other undergo element diffusion at high temperature and high pressure, leading to changes in the composition and structural properties of the material, which in turn reduces the tool's service life. An understanding of the bond and the breakage behavior of the rake face can provide a basis for better exploration of the formation of the tool rake face during the cutting process. A combination of innovative experimental methods and powerful data analysis software to explore hard alloys and the influences of adhesion on the rake face of the tool on the element diffusion behavior and the tool components are used in this study. However, this is a difficult research area because the element diffusion of the tool and workpiece material is a dynamic process. In this study, the process of stick-welding on the rake face of the tool is analyzed during the cutting process and clamped and welded specimens that held at a given temperature for different time periods are used to simulate the states of the non-stick-welding and stick-welding respectively after diffusing; subsequently, the hardness of the tool surface is measured. The behavior of the element diffusion for the non-stick-welding and stick-welding during the cutting process is analyzed and the influence on the element diffusion and the cutting performance are discussed and analyzed.

\section{Process of tool-chip adhesion on the rake face}

In order to better understand the tool-chip sticking phenomenon during the cutting process of difficult-to-process materials, we chose a material that adheres easily to the workpiece to facilitate the observation and analysis of the temperature and pressure produced by the adhesive layer on the rake face of the carbide tool and the microstructure of the formed adhesive layer. We used stainless steel $1 \mathrm{Cr} 18 \mathrm{Ni} 9 \mathrm{Ti}$ containing a high $\mathrm{Cr}$ and $\mathrm{Ni}$ content; Ni provides a relatively stable austenite structure and $\mathrm{Cr}$ reduces the ability of the materials to resist adhesion; this facilitates the adhesion between the workpiece material and tool material. The carbide tool YT15 was used. Various cutting parameters were used for an in-depth analysis of the tool-chip sticking and the thermal conditions. In the test, the cutting depths were $2 \mathrm{~mm}, 2.5 \mathrm{~mm}$, and $3 \mathrm{~mm}$, the feed rate range was $0.3 \mathrm{~mm} / \mathrm{r}-0.4 \mathrm{~mm} / \mathrm{r}$, and the cutting speed range was $60 \mathrm{~m} / \mathrm{min}-240 \mathrm{~m} / \mathrm{min}$.

The cutting experiment was carried out on a C6140 lathe; the cutting test system is shown in Fig.2. A ThermovisionA40M infrared camera was used to obtain the cutting temperature near the cutting edge and the shooting time began when the tool cut into the workpiece and ended when the cutting was completed and the tool was retracted. The tool-chip contact at the carbide tool's rake face was recorded in real-time with a high-speed camera during the cutting process. The microscopic morphology and element concentration distribution of the rake face were analyzed by SEM.

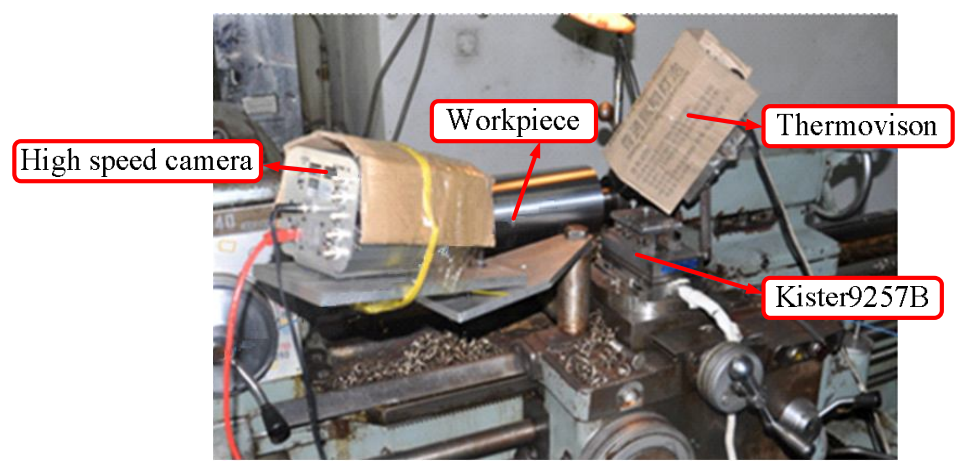

Fig. 2 Stainless steel turning test system

The analysis of the temperature and cutting force during the cutting process showed the tool-chip contact when the chips moved through the rake face and the high-speed camera results captured the cutting process as chip contacted the rake face until damage occurred. It is found that the rake face of the tool is welded serious when the cutting parameters are $v_{\mathrm{c}}=150 \mathrm{~m} / \mathrm{min}, a_{\mathrm{p}}=2.5 \mathrm{~mm}$, and $f=0.35 \mathrm{~mm} / \mathrm{r}$. The cutting force data of the cutting parameters captured by the dynamometer show that the turning force is very unstable, as shown in Fig. 3(a). It is assumed that the tool-chip contact area is $8 \mathrm{~mm}^{2}$ during the cutting process under the given cutting parameters and the contact area of the tool-chip contact is equal. The minimum $F_{\mathrm{z}}(300 \mathrm{~N})$ of the experimental process is the pressure of the tool-chip contact zone of $37.5 \mathrm{MPa}$ after the positive pressure calculation, which reached the magnitude of the diffusion welding (Zhu et al., 2008). It can be seen that the tool-chip force in the tool-chip contact area during the cutting process results in the mutual diffusion of 
the elements. In addition, the temperature of the tool-chip contact area reaches more than $1000^{\circ} \mathrm{C}$ and the average temperature is approximately $800^{\circ} \mathrm{C}$; a red flame appears in many cases, as shown in Fig. 3(b).



(a)

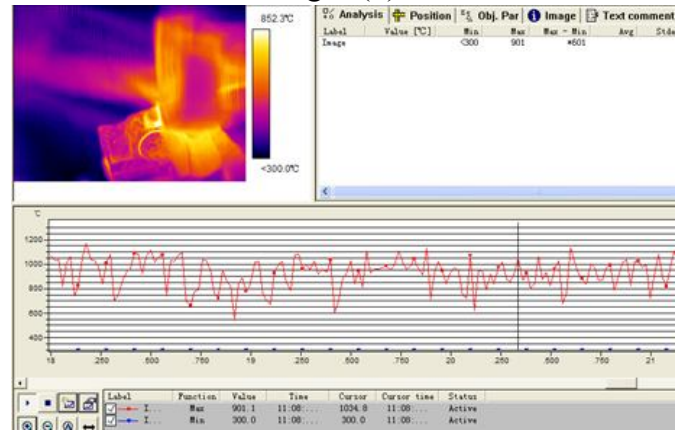

(b)

Fig. 3 Cutting force and cutting temperature under the cutting parameters of cutting speed $v_{\mathrm{c}}=150 \mathrm{~m} / \mathrm{min}$, feed rate $f=0.35$ $\mathrm{mm} / \mathrm{r}$, and cutting depth $a_{\mathrm{p}}=2.5 \mathrm{~mm}$; (a) cutting force; (b) cutting temperature

The area of the tool where the adhesion phenomenon occurs is cut along the longitudinal plane and is ground and polished. The interface microstructure and element concentrations are shown in Fig.4. As can be seen from Fig.4, the tool-chip material is tightly packed and there is no lack of contact in the middle or change in the microstructure near the interface between the tool and the chip; this indicates that a solid weld was formed between the two materials and that the weld strength exceeded the bond strength inside the cemented carbide. The SEM results indicated the element concentration at the tool-chip adhesion interface; the elements with higher contents and more obvious diffusion in the bond interface were selected for analysis and it was found that the tool contained a certain amount of Fe and the workpiece contained a certain amount of $\mathrm{W}$, which illustrates the occurrence of the element diffusion between the tool and workpiece materials.

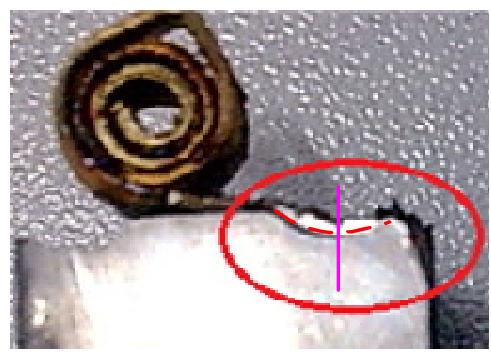

(a)

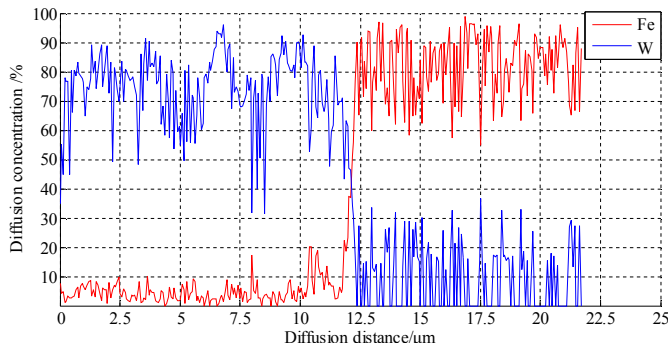

(b)

Fig.4 Tool-chip adhesion interface; (a) adhesion and its position at the rake face; (b) concentration distribution of the major elements at the diffusion interface (red and blue lines represent Fe and $\mathrm{W}$ respectively)

The results shown in Fig. 2, 3, and 4 demonstrate that the tool rake face exhibits a certain amount of adhesion during the start of the cutting process and as the adhesion increases, the tool rake face is covered by the adhesion at a cutting temperature of approximately $800^{\circ} \mathrm{C}$. At this time, the pressure at the tool-chip contact area reaches the magnitude of the pressure of diffusion welding. During the cutting process, high heat is generated because of the high temperature and when the cutting speed is low and the material has a slow heat dissipation and good ductility, the material will partially melt on the rake face, resulting in a "sticking tool" phenomenon. Carbide is based on Co and during the bonding phase, a connection and wetting of the hard phase occur by sintering; therefore, the surface is not smooth and "micro-bulges" appear. As a result, the friction and bite of the chips causes some of the chips to remain on the surface in the early cutting stage, resulting in a small amount of adhesion; at this time, the rake face mainly exhibits wear. As the cutting time increases, the material bonded to the rake face is continuously pressed and sheared by the continuous influx of chips, and the element diffusion under high temperature and pressure causes changes in the composition and performance of the tool rake face. With increased adhesion, a stable sticking area is eventually formed under the action of high temperature and pressure, friction, and extrusion.

Pressure diffusion welding generally goes through three stages: the first stage is the friction process and the pure metal surface is exposed because of the mutual friction between the contacts; this eliminates the oil, oxides, etc. on the surface of the workpiece, causing the friction to expand from an initial point to the surface. The second stage is marked by increases in the temperature of the contact surface and the deformation resistance decreases as a result of the repeated friction. Under the combined action of the static pressure and alternating shearing stress, the surface of the 
weld undergoes a plastic flow, prompting the atoms of the pure metal to approach the range of gravitational attraction and atomic diffusion and interaction and even recrystallization occur. The third stage is the friction process, during which the contact area increases, forming a plastic flow layer within the welded zone and the mechanical bite between the weld emerges. There are fewer occlusion points in the early stage and the occlusion area is small; therefore, they can be destroyed easily. The number and area of the biting points increase in the later period and a solid joint is formed when the shear force is larger than the binding force. The formation of the adhesion zone is similar to that of the pressure diffusion welding and occurs under the action of pressure and friction on the contact surface; the area of bonding changes from small to large and is accompanied by the transfer of elements, ultimately forming a stable bond or a solid joint. The appearances of the tool-chip adhesion areas and the joint are shown in Fig.5, indicating a firm bond. Therefore, the experiment of the clamped and welded specimens was used to simulate the non-stick-welding and stick-welding during the cutting process and to explore the effect of stick-welding on the element diffusion.

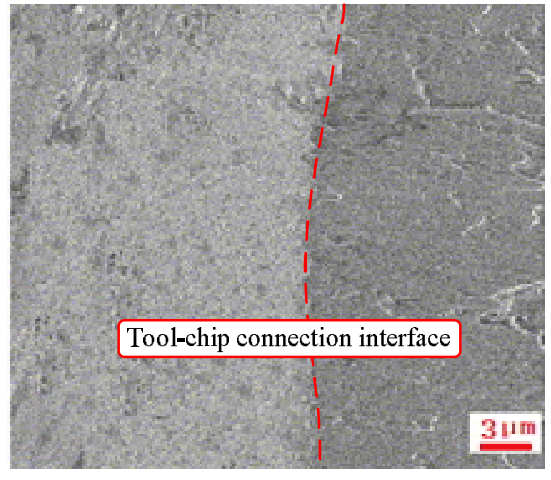

(a) Tool-chip adhesion zone

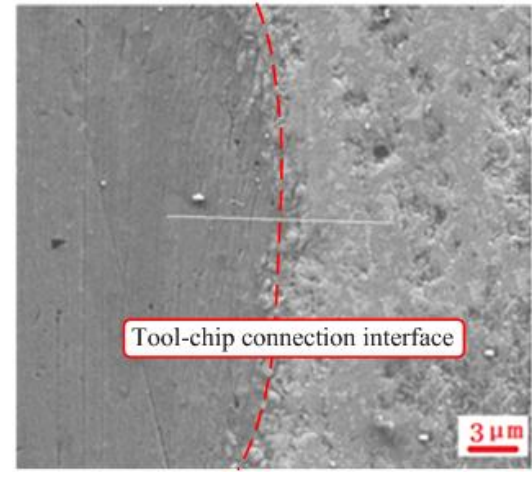

(b) Joint of pressure welding

Fig. 5 Micro-morphology of the diffusion interface

\section{Diffusion experiment}

\subsection{Establishment of the experimental system}

The cutting force and heat and the microstructure of the bonding interface were analyzed and the experimental system was established based on the adhesive layer formation of the cemented carbide rake face. The two methods of clamping and welding are used to prepare the diffusion couple experiment. The preparation of the clamped specimens was conducted as follows. The stainless steel was directly machined into rectangular sheets and the shape was consistent with the carbide tool; a hole with a diameter of $6 \mathrm{~mm}$ was created in the middle of the stainless steel sheet and the carbide tool was fastened to the stainless steel sheet by bolts. The preparation of the welded specimens was as follows. After fixing the stainless steel sheet and the carbide blade with bolts, the solder whose components were compatible with the stainless steel sheet material was melted and welded together with the carbide tool. The surface of the diffusion couple was ground and polished and the effect after polishing is shown in Fig. 6.

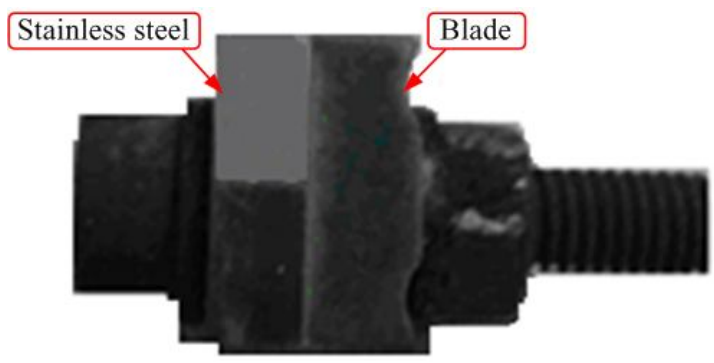

(a) Clamped specimens

Fig. 6 Diffusion specimens

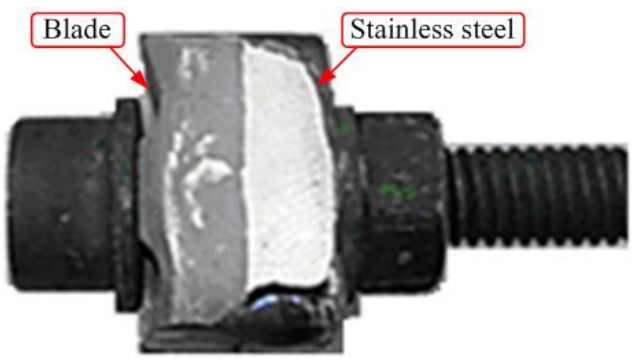

(b) Welded specimens

The diffusion couple experiment was used to explore the influence of the heat preservation time and the stick-welding on the diffusion concentration of the elements. Due to the continuous flow of chips during the cutting process, the rake face of the tool is always in contact with the chip surface; therefore, the clamped specimens that are held for $15 \mathrm{~min}, 30 \mathrm{~min}$, and $180 \mathrm{~min}$ at $800^{\circ} \mathrm{C}$ are used to simulate the tool-chip element diffusion at different times when there is no adhesion on the rake face. During the continuous cutting process, the workpiece material adheres to the rake face of the tool and the stick-welded layer is finally formed; the diffusion couple experiment with the welded 
parts is used to simulate the diffusion of the tool-chip elements. The cutting process continues after the adhesion occurrence; therefore, the welded diffusion couple experiments (with specimens held for 15min, 30min, and 180min at $800^{\circ} \mathrm{C}$ ) is used to simulate the element diffusion conditions for different cutting times after the formation of the stick-welded layer. During the experiment, a furnace is used for heating and heat-holding, as shown in Fig. 7.

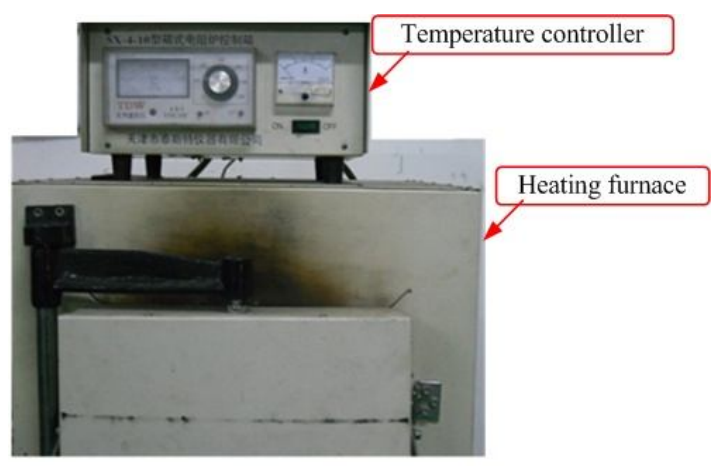

\subsection{Results and discussion}

Fig. 7 Heating and heat-holding equipment

\subsubsection{Element diffusion analysis of tool-chip}

The results of the surface treatment of the clamped specimens after holding for $15 \mathrm{~min}, 30 \mathrm{~min}$, and $180 \mathrm{~min}$ at $800^{\circ} \mathrm{C}$ and the energy spectrum analysis are shown in Fig. 8.

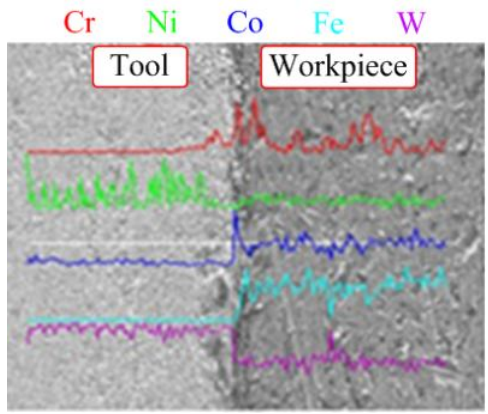

(a)

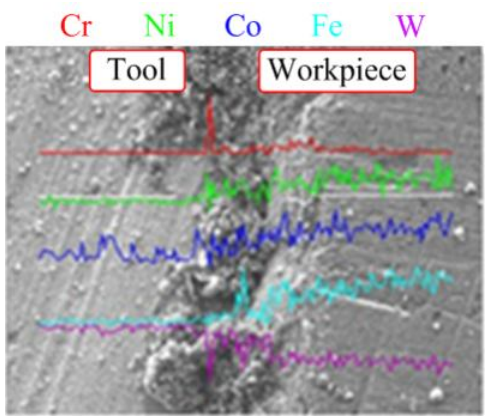

(b)

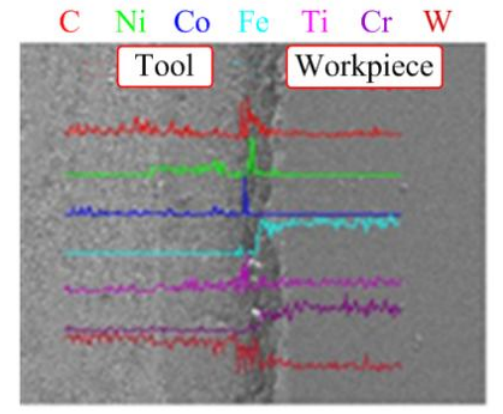

(c)

Fig.8 Element concentration distribution of $\mathrm{C}, \mathrm{Ti}, \mathrm{Co}, \mathrm{Cr}, \mathrm{Fe}$, and $\mathrm{W}$ for the clamped specimens at different holding times at $800^{\circ} \mathrm{C}$; (a) $15 \mathrm{~min}$; (b) $30 \mathrm{~min}$; (c) $180 \mathrm{~min}$

The results show that the diffusion distance of the elements differs for different holding times for the clamped specimens; for the same element, the diffusion distance increases with the increase in the holding time and the diffusion rates of $\mathrm{Fe}$ and $\mathrm{W}$ are significantly higher than those of the elements with a lower content at the same holding time. The diffusion concentration values of $\mathrm{Fe}$ and $\mathrm{W}$ at the side of the tool for the different holding times are obtained from Fig. 8 and the element concentration curve is drawn, as shown in Fig. 9.

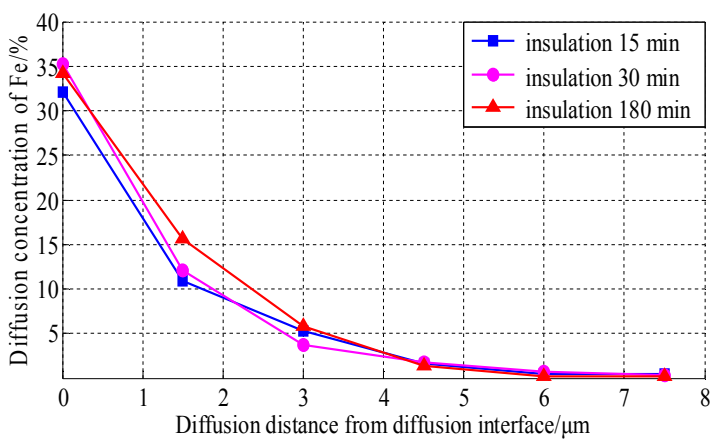

Fig.9 Fe concentration curve of the clamped specimens for different holding times. The blue line, the purple line, and the red line represent the Fe concentration at different positions of the diffusion interface at different holding times

Fig.9 shows the element diffusion of $\mathrm{Fe}$ for the three holding times at the diffusion temperature of $800^{\circ} \mathrm{C}$ for the clamped specimens. There is an apparent change trend in the diffusion concentration but the concentrations do not 
increase significantly for the different holding times. The diffusion concentration of $\mathrm{Fe}$ increases with the increase in the holding time within $6 \mu \mathrm{m}$ near the diffusion interface and it increases consistently with the increase in the distance from the diffusion interface. By analyzing the behavior of the Fe concentration of the tool, it is evident that an initial adhesion occurred when cutting the stainless steel $1 \mathrm{Cr} 18 \mathrm{Ni}$ Ti with the carbide tool. The diffusion of Fe in the tool and the workpiece material takes place at a certain pressure and the temperature of the contact zone reaches a certain temperature. The element diffusion markedly increases with the cutting time, which indicates that the cutting time does have a certain impact on the concentration. Therefore, when the cutting temperature reaches the temperature at which adhesion occurs, it is necessary to control the cutting time to avoid the increase in the element diffusion on the rake face and reduce the tool bond damage.

The results of the surface treatment of the welded specimens after holding for $15 \mathrm{~min}, 30 \mathrm{~min}$, and $180 \mathrm{~min}$ at $800^{\circ} \mathrm{C}$ and the energy spectrum analysis are shown in Fig. 10.

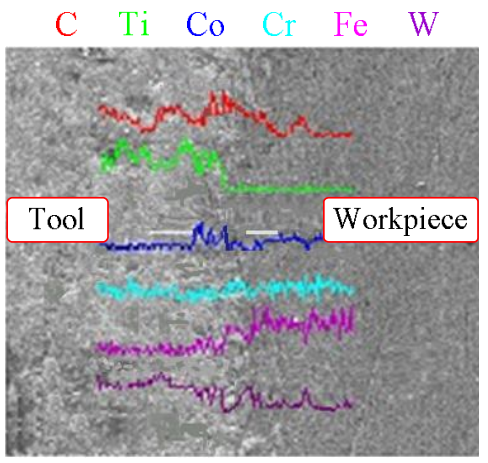

(a)

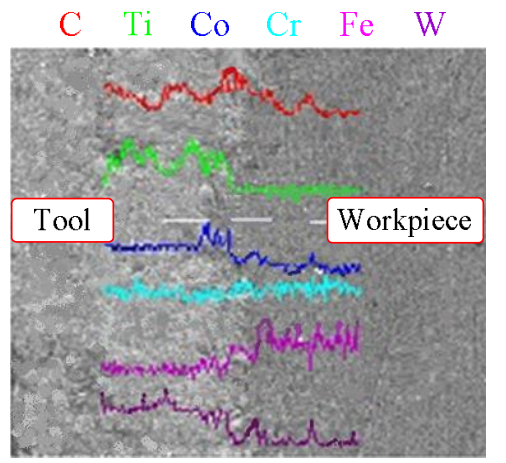

(b)

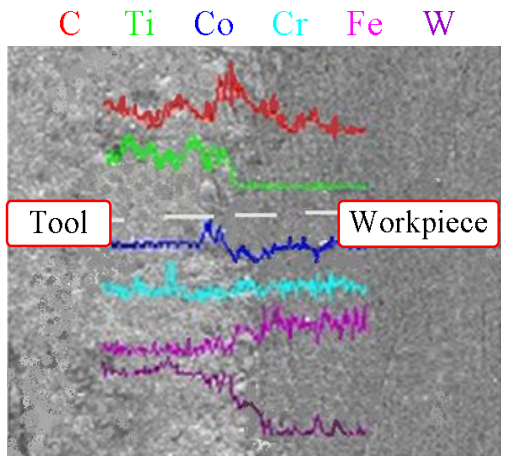

(c)

Fig.10 Element concentration distribution of $\mathrm{C}, \mathrm{Ti}, \mathrm{Co}, \mathrm{Cr}, \mathrm{Fe}$, and $\mathrm{W}$ for the welded specimens at different holding times at $800^{\circ} \mathrm{C}$; (a) $15 \mathrm{~min}$; (b) $30 \mathrm{~min}$; (c) $180 \mathrm{~min}$

Similarly, the diffusion concentration of the Fe on the side of the tool for the different holding times is determined and the Fe concentration is shown in Fig.11. It is evident that the change trends of the element concentration are consistent with those of the clamped specimens for the different holding times; as the holding time increases, the concentration of the element diffusion increases but the changes are relatively small.

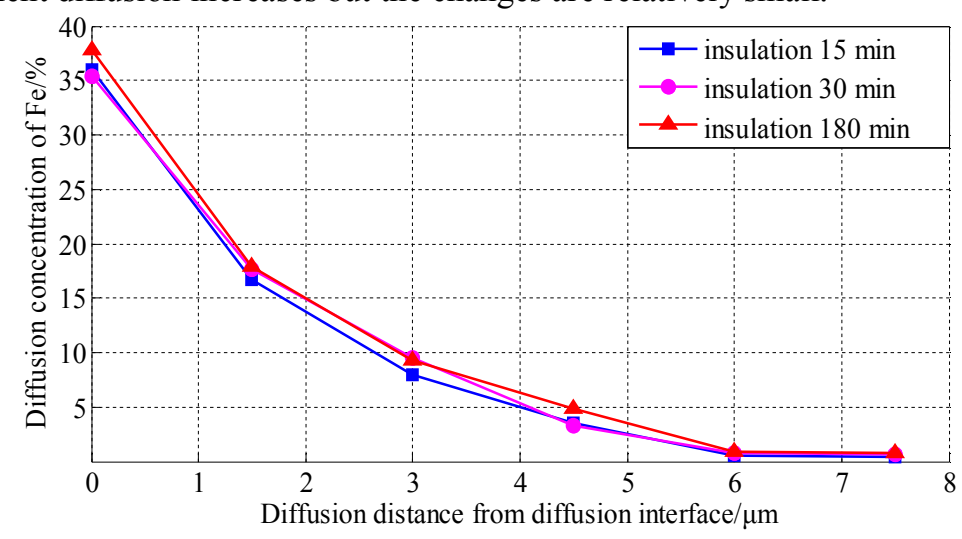

Fig. 11 Fe concentration of the welded specimens at different holding times. The blue line, the purple line, and the red line represent the Fe concentrations corresponding to different positions of the diffusion interface at different holding times

In order to further investigate the influences of the stick-welding on the element diffusion for the clamped and welded specimens, the diffusion concentration curves of Fe and $\mathrm{W}$ are determined for a holding time of $180 \mathrm{~min}$ and the results are shown in Fig. 12.

The results show that for the same holding time, the effect is the same for the welded and clamped specimens for the same element but the effect differs for Fe and W. The diffusion concentration and rate are slightly higher for the welded specimens than for the clamped specimens for Fe; however the diffusion concentration of $\mathrm{Fe}$ tend to be consistent away from the interface, which indicates that the stick-welding has a small effect on the diffusion rate and concentration of $\mathrm{Fe}$ at a distance of a few microns from the interface but there is essentially no effect on the final concentration. However, the diffusion concentration of $\mathrm{W}$ is higher for the welded specimens than the clamped 
specimens and there is no influence on the final concentration, which means that the stick-welding has an effect on the diffusion of $\mathrm{W}$ and facilitates the diffusion of $\mathrm{W}$ to some extent.



Fig. 12 Element concentration of the welded and clamped specimens for a holding time of $180 \mathrm{~min}$. The red lines with triangles and blue lines with circles represent the Fe inflow and $\mathrm{W}$ outflow

\section{2 .2 Intluence of the tool-chip adhesion on the element dittusion coefticient}

It can be seen from the results of these experiments that regardless of non-stick-welding and stick-welding, the element concentration increases with the increase in the holding time and the concentration remains unchanged at a certain distance from the interface. In the case of the constant holding time, the stick-welding facilitates the element diffusion; the impact on Fe is small whereas the effect on W is more pronounced. Fick's second law is used to quantitatively describe the concentration distribution of the elements for a certain state and the influence of the stick-welding on the element diffusion is investigated by calculating the diffusion coefficients of Fe and W.

During the cutting process, a tool-chip contact occurs on the rake face of the carbide tool and the diffusion of the tool and workpiece material are dissimilar due to the different materials and the element concentration varies with time; therefore, the diffusion equation in an unsteady situation is established using Fick's second law. The retention of the workpiece material on the rake face is caused by thermal stress induced by friction at the contact area between the chip and tool rake face. This happens continuously and results in bonding; therefore, the infinite diffusion model is chosen to describe the element diffusion state on both sides. The model is shown in Fig. 13.
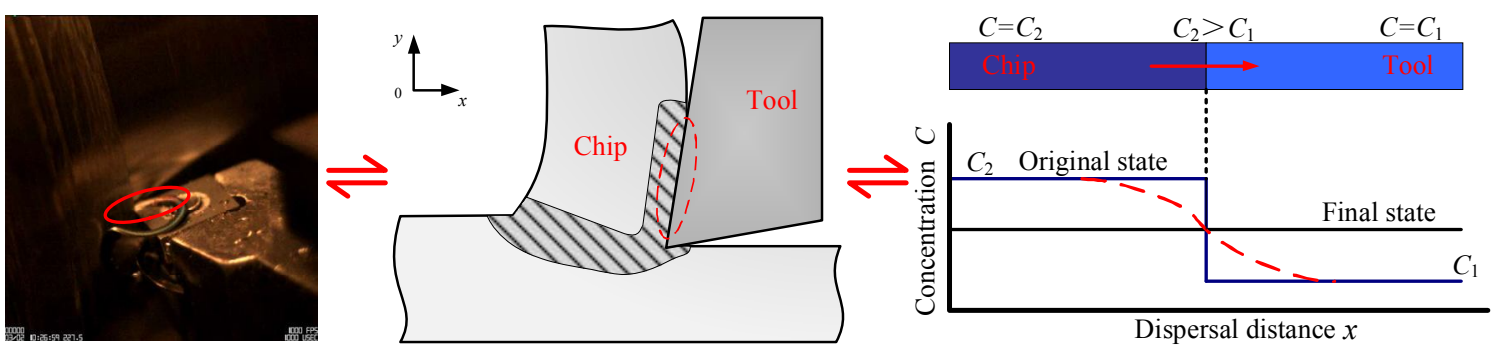

Fig. 13 Tool-chip element diffusion model

The diffusion equation for the transition region of the interface is given by Fick's second law in the unsteady state:

$$
\frac{\partial C}{\partial t}=D \frac{\partial^{2} C}{\partial x^{2}}
$$

where $x=\sqrt{\mathrm{t}} \lambda$; the evolution of Eq. (1) can be written in the following form:

$$
-2 D \frac{d^{2} C}{d \lambda^{2}}=\lambda \frac{d C}{d \lambda}
$$

The general solution of Eq. (2) obtained by the substitution method is as follows:

$$
C=\mathrm{A} \int{ }_{0}^{\lambda} \exp \left(-\frac{\lambda^{2}}{4 D}\right) d \lambda+B
$$

where $\beta=\lambda /(2 \sqrt{D})$; the evolution of the Eq. (2) is given by the Gaussian function:

$$
C=\mathrm{A} \int{ }_{0}^{\beta} \exp \left(-\beta^{2}\right) d \beta+B
$$


where $C$ is the concentration of the element, $D$ is the diffusion coefficient, $x$ is the diffusion distance, $A$ is the concentration range of the corresponding element, and $B$ is the element concentration at the central interface.

The solution of the equation is determined by combining the initial and boundary conditions of the diffusion element concentration in the combined interface.

The initial conditions are defined as follows:

$$
\begin{cases}C(x>0, & t=0)=C_{1} \\ C(x<0, & t=0)=C_{2}\end{cases}
$$

The boundary conditions are defined as follows:

$$
\left\{\begin{array}{l}
C(x=+\infty, t>0)=C_{1} \\
C(x=-\infty, t>0)=C_{2}
\end{array}\right.
$$

$C_{1}$ and $C_{2}$ are obtained respectively by Eq. (4) and the boundary condition is as follows:

$$
C_{1}=A+\operatorname{Berf}\left(\frac{+\infty}{2 \sqrt{D t}}\right), C_{2}=A+\operatorname{Berf}\left(\frac{-\infty}{2 \sqrt{D t}}\right)
$$

According to $\operatorname{erf}(+\infty)=1, \operatorname{erf}(-\infty)=-1$; therefore, $C_{1}$ and $C_{2}$ can be expressed respectively as follows:

$$
C_{1}=A+B, C_{2}=A-B
$$

where $t$ and $x$ are respectively the diffusion occurring after a period time and the solute concentration distributed along the $x$-direction. When $A$ and $B$ are plugged into Eq.(4), the formula of the element diffusion concentration can be written as follows $(\mathrm{Xu}, 2014)$ :

$$
\mathrm{C}(x, t)=\frac{\mathrm{C}_{1}+\mathrm{C}_{2}}{2}+\frac{\mathrm{C}_{1}-\mathrm{C}_{2}}{2} \operatorname{erf}\left(\frac{x}{2 \sqrt{D t}}\right)
$$

where $C_{1}$ is the initial concentration of an element in the workpiece material, $C_{2}$ is the initial concentration of an element in the tool material, $t$ is the diffusion time, and $\operatorname{erf}(\beta)$ is the complementary error function.

According to Eq. (9), the origin of the data processing software is used to nonlinearly fit the element concentration distributions of Fe and $\mathrm{W}$ for the clamped and welded specimens held for 180min respectively, as shown in the Fig. 14.
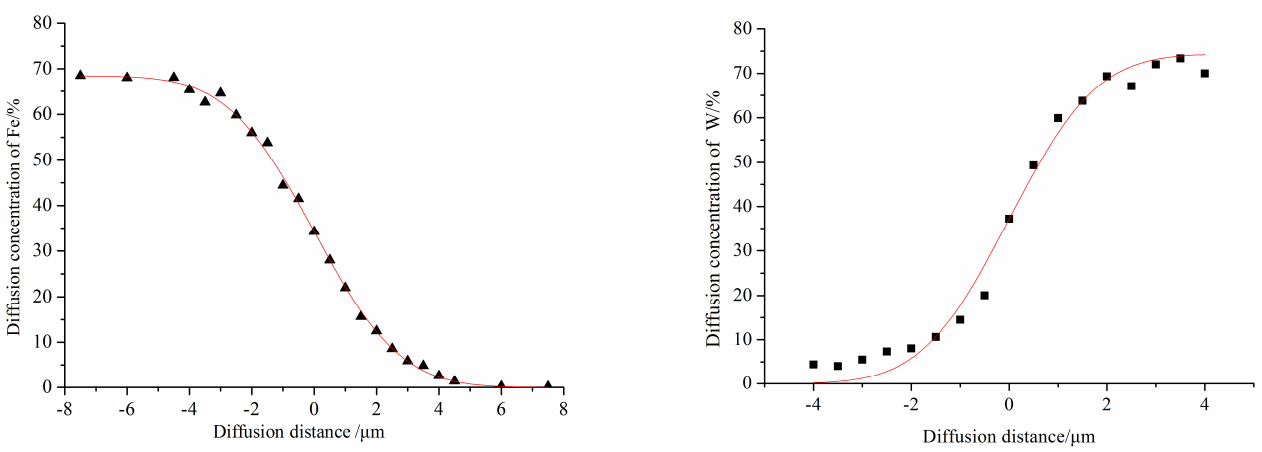

(a) Adhesion without forming
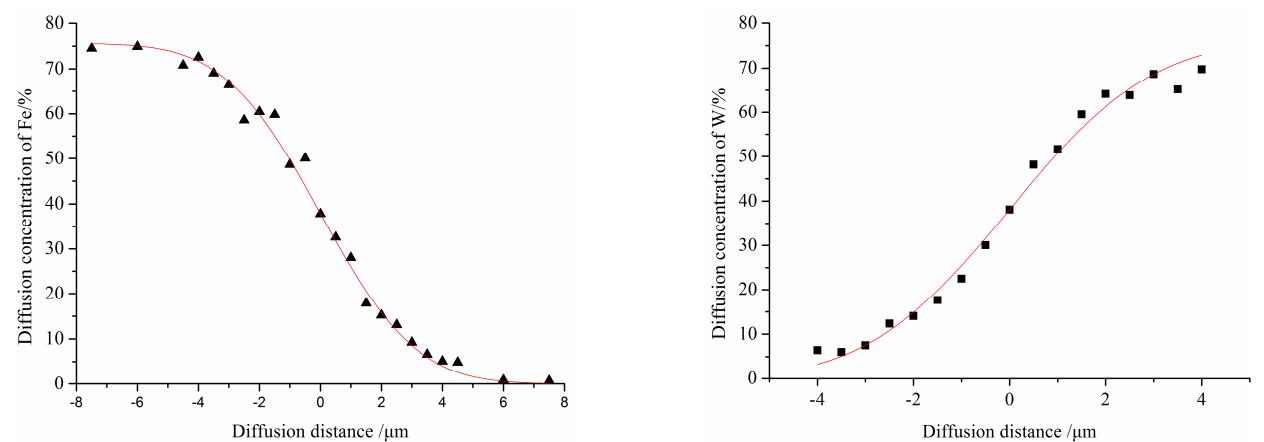

(b) Adhesion formation

Fig.14 Fitted curves of the element concentration distribution; (a) fitted curves of Fe and W before adhesion formation; (b) fitted curves of Fe and $\mathrm{W}$ when adhesion occurs

Fig. 14 shows the four fitted curves. The diffusion coefficient of $\mathrm{Fe}$ and $\mathrm{W}$ for the clamped and welded specimens 
can be obtained by fitting the curve, as shown in Table 1.

Table 1 Diffusion coefficient of $\mathrm{Fe}$ and $\mathrm{W}$ for the clamped and welded specimens

\begin{tabular}{c|c|c}
\hline \hline & Clamped specimens & Welded specimens \\
\hline Fe diffusion coefficient $\left[\mathrm{m}^{2} / \mathrm{s}\right]$ & $2.21 \times 10^{-14}$ & $2.84 \times 10^{-14}$ \\
\hline W diffusion coefficient $\left[\mathrm{m}^{2} / \mathrm{s}\right]$ & $9.2 \times 10^{-15}$ & $2.52 \times 10^{-14}$ \\
\hline
\end{tabular}

According to Table 1, the diffusion coefficient is higher for the welded specimens than the clamped specimens for Fe and W. The diffusion coefficient is a physical quantity that describes the material diffusion capacity and is expressed by the mass or mole number of the substances diffusing vertically through a unit area along the direction of diffusion.

According to the diffusion coefficient formula $D=D_{0} \exp \left(-\frac{Q}{R T}\right)$, the most important factor that influences the

diffusion coefficient is the temperature; in addition, the structure of the diffusion phase medium, structural defects, and impurities also affect the diffusion coefficient. In the case of the stick-welding layer, the structure of the diffusion phase is different for the substrate and the bonding zone, which causes the distortion of the stress field near the diffusion medium, and vacancy defects can occur. In the substrate of the tool, the increase in the Fe depends on the number of impurities, and if this occurs in conjunction with vacancy defects in the substrate, the number of vacancies will increase, which promotes the diffusion and the diffusion coefficient under the same temperature conditions will increase.

\subsubsection{Influence of the element diffusion on the hardness at the tool surface and analysis of breakage morphology}

The tool specimens after the clamped diffusion experiment with the 180 -min holding time are used as the sample pieces. Alcohol is used to wash the surface of the tool and four points are selected respectively on the contact and untouched surfaces between the tool and workpiece, as shown in Fig. 15.

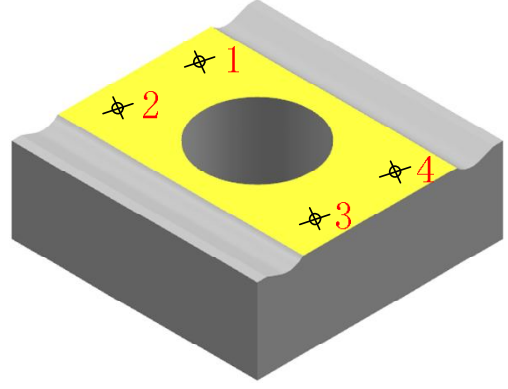

(a) Untouched surface

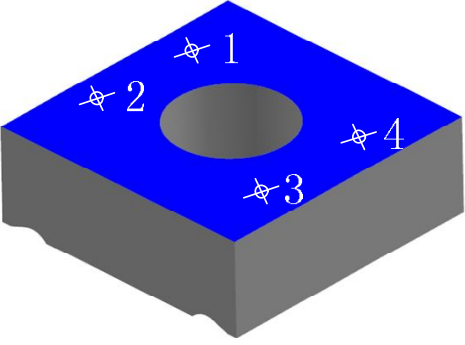

(b) Contact surface

Fig. 15 Diagram of hardness measurements on the surface of the tool

The hardness value of the points are measured with a micro-hardness tester and the results are shown in Table 2.

Table 2 Hardness value of the points on the surface of the tool

\begin{tabular}{c|c|c|c|c}
\hline \hline \multirow{2}{*}{ Type } & \multicolumn{4}{|c}{ Hardness value of the points[HV] } \\
\cline { 2 - 5 } & 1 & 2 & 3 & 4 \\
\hline Contact surface & 904 & 850 & 915 & 936 \\
\hline Untouched surface & 1350 & 1450 & 1320 & 1380 \\
\hline
\end{tabular}

The hardness value of the tool surface that is in contact with the workpiece is $850-936 \mathrm{HV}$, whereas the hardness value of the untouched surface is in the range of $1320-1450 \mathrm{HV}$, representing a decrease in hardness number of about $30 \%$. The contact surface is identical to the non-contact surface with regard to temperature, pressure, etc. but because of the contact with the workpiece, the contact surface is affected by the workpiece material and the loss of the tool's elements, which causes the changes in the composition and structure of the contact surface, thereby affecting its hardness value.

Fig. 16 shows the rake face of the tool after breakage under microscope with super wide depth of field. The tool breakage usually occurs near the maximum depth of the rake face and the depth of the breakage is in the range of $100-300 \mu \mathrm{m}$. 


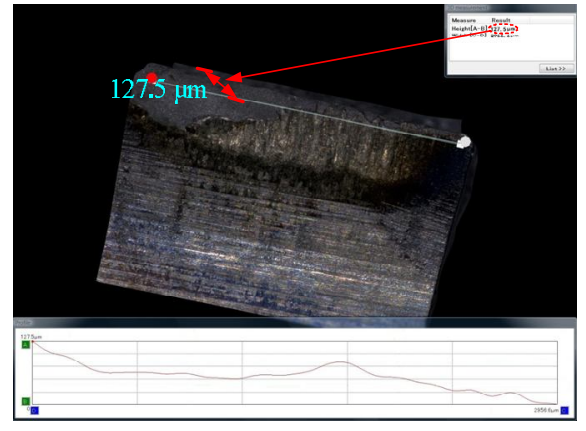

(a)

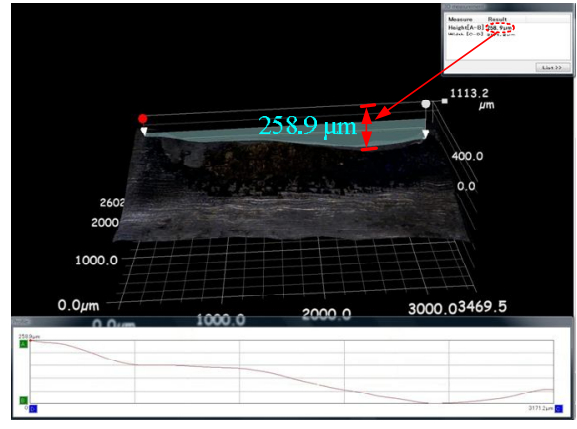

(b)

Fig.16 Tool breakage for different cutting parameters by microscope with super wide depth of field; (a) cutting speed $v_{\mathrm{c}}$ $=150 \mathrm{~m} / \mathrm{min}$, feed rate $f=0.30 \mathrm{~mm} / \mathrm{r}$, and cutting depth $a_{\mathrm{p}}=2.5 \mathrm{~mm} ;$ (b) cutting speed $v_{\mathrm{c}}=180 \mathrm{~m} / \mathrm{min}$, feed rate

$f=0.30 \mathrm{~mm} / \mathrm{r}$, and cutting depth $a_{\mathrm{p}}=3 \mathrm{~mm}$

According to the element diffusion and the diffusion formula, the diffusion depth of the Fe in the workpiece and

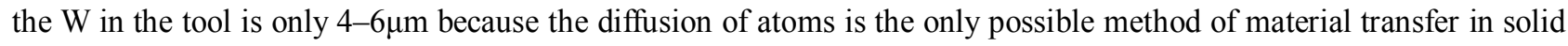
materials; however, due to the action of the surrounding atoms, the diffusion process needs to overcome certain barriers. The diffusion becomes more difficult and the diffusion distance decreases but the influence of the diffusion element on the tool itself is significant. This is because under high temperatures, element inter-diffusion occurs between the cutting tool material and the workpiece material and the outflow of $\mathrm{W}$ and $\mathrm{Co}$ and the inflow of Fe in the carbide tool changes the composition and structure of the cutting tool; therefore, the initial crack extends to the tool substrate. However, the crack stops or shifts when the strengthening phase occurs, leading to an increase in the hardness in the depth direction. Therefore, although the diffusion of the elements is only a few microns, the damage depth of the tool can be as high as $200 \mu \mathrm{m}$.

\section{Conclusions}

(1) A cutting test was carried out to analyze the formation of tool-chip adhesion under different force and thermal conditions and the element diffusion was investigated during the cutting process in conjunction with pressure diffusion welding; it is evident that the effects of tool-chip adhesion on the rake face are similar to those of pressure diffusion welding.

(2) Clamped and welded specimens were used to simulate non-stick and stick-welding, respectively. Because the $\mathrm{W}$ content is higher in the tool and the Fe content is higher in the workpiece material, the diffusion behavior is apparent. The concentration distribution results show that the element concentration increases with increasing holding time and remains unchanged at a certain distance from the interface regardless of the welding type. For certain holding times, the stick-welding promotes the element diffusion and the effect is smaller for Fe and more pronounced for W.

(3) Fick's second law was used to establish a theoretical model of tool-chip element diffusion; the diffusion coefficients were obtained for $\mathrm{Fe}$ and $\mathrm{W}$ for the clamped and welded specimens held for 180min. Moreover, the diffusion coefficient is always higher for the welded specimens, which further confirmed the effect of the stick-welding on the element diffusion.

(4) Microscope with super wide depth of field was used to observe the tool breakage. The observations and the results of the tool surface hardness test of the contact and untouched zone of the workpiece indicate that the hardness value decreases by about $30 \%$ and that the effect of element diffusion concentration on the tool breakage is significant.

\section{Acknowledgements}

This work was supported by the National Natural Science Foundation of China (51575146) and the Education and Research Project for young and middle-aged teachers of Fujian Province, China (JAT170506). The authors would like to sincerely appreciate all the support. 


\section{References}

ARashid, R. A. R., Palanisamy, S., Sun, S., and Dargusch, M. S., Tool wear mechanisms involved in crater formation on uncoated carbide tool when machining Ti6Al4V alloy, International Journal of Advanced Manufacturing Technology, Vol.83, No.9-12 (2016), pp.1-9.

Bai, D. S., Sun, J. F., Chen, W. Y., and Du, D. X., Molecular dynamics simulation of the diffusion behaviour between $\mathrm{Co}$ and $\mathrm{Ti}$ and its effect on the wear of $\mathrm{WC} / \mathrm{Co}$ tools when titanium alloy is machined, Ceramics International, Vol.42, No.15 (2016), pp. 17754-17763.

Calatoru, V. D., Balazinski, M., Mayer, J. R. R., Paris, H., and L'Espérance, G., Diffusion wear mechanism during high-speed machining of 7475-T7351 aluminum alloy with carbide end mills, Wear, Vol.265, No.11-12 (2008), pp. 1793-1800.

Chen, J. G., Zheng, M. L., Li, P. F., Feng, J. Y., and Sun, Y. S., Experimental study and simulation on the chip sticking-welding of the carbide cutter's rake face, International Journal on Interactive Design \& Manufacturing, No.3(2017), pp.1-11.

Deng, J. X., Li, Y. S., and Song, W. L., Diffusion wear in dry cutting of Ti-6Al-4V with WC/Co carbide tools, Wear, Vol. 265, No.11 (2008), pp.1776-1783.

Deng, J. X., Li, Y. S., and Zhang, H., Adhesion wear on tool rake and flank faces in dry cutting of Ti-6Al-4V, Chinese Journal of Mechanical Engineering, Vol. 24, No.6(2011), pp. 1089-1094.

Fan, Y. F., Hao, Z. P., Lin, J. Q., and Yu, Z. X., Material response at tool-chip interface and its effects on tool wear in turning Inconel718, Materials \& Manufacturing Processes, Vol.20, No.11-12 (2014), pp. 1446-1452.

Matsui, N., Sano, N., Fujiwara, J., Ohishi, K., Ohkubo, T., and Hono, K., Microscopic observation of the interface between a tool surface and deposits of low-carbon free cutting steel, Materials Transactions, Vol.53, No.6 (2012), pp. 1130-1137.

Molinari, A., and Nouari, M., Modeling of tool wear by diffusion in metal cutting, Wear, Vol.252, No.1 (2002), pp.135-149.

Ramirez, C., Ismail, A. I., Gendarme, C., Dehmas, M., Aeby-Gautier, E., Poulachon, G., and Rossia, F., Understanding the diffusion wear mechanisms of WC-10\%Co carbide tools during dry machining of titanium alloys, Wear, Vol. 390-391, No.11 (2017), pp.61-70.

Soković, M., Kosec, L., and Dobrzański, L.A., Diffusion across PVD coated cermet tool/workpiece interface, Journal of Materials Processing Technology, Vol.s157-158, No.1 (2004), pp. 427-433.

Sun, Q.Q., and Lu, S., Elements diffusion and mechanical properties of 15-5PH stainless steel joint brazed with BNi-2 filler metal, Materials Science Forum, Vol.850 (2016), pp. 700-705.

Tong, J. G., Gao, X. D., Qu, H. T., Zou, S. W., Li, S. X., and Ren, X. P., Diffusion behavior of Cr element at the bonding interface of a 25CrSMoA/Q235 solid-liquid cladding shaft, Journal of University of Science and Technology Beijing, Vol.31, No.4 (2009), pp.451-457 (in Chinese).

$\mathrm{Xu}, \mathrm{X}$., Research on diffusion resistance of WC-Ni3A1 according to cutting of 0Cr18Ni9 stainless steel, M.A. Dissertation, South China University of Technology, Guangzhou, China, (2014).

Zhang, S., Li, J. F., Deng, J. X., and Li, Y. S., Investigation on diffusion wear during high-speed machining Ti-6Al-4V alloy with straight tungsten carbide tools, International Journal of Advanced Manufacturing Technology, Vol. 44, No.1-2 (2009), pp. 17-25.

Zhu, J. L., Huang, J. H., Zhang, H., and Zhao, X. K., Progress in research on welding of cemented carbide with steel, Welding \& Joining, Vol.2 (2008), pp.15-19 (in Chinese). 